\title{
LA INMIGRACIÓN IRREGULAR DE AFRICANOS EN ESPAÑA, BALANCES Y PERSPECTIVAS
}

\author{
Vicente Gozálvez Pérez
}

\section{RESUMEN}

Los africanos son el colectivo extranjero en España que más se ha incrementado durante la última década; la mayoría se instaló de modo irregular, aunque con posterioridad se han regularizado en alta proporción, sobre todo a través de las Regularizaciones extraordinarias $(1985-86,1991,1996)$ y de los permisos de trabajo ofertados en los Contingentes anuales para trabajadores extranjeros no comunitarios (1993-1998). En esta línea se destacan las principales acciones derivadas de la política española de inmigración. La agricultura mediterránea española, por sus características, es utilizada como «puerta», o primera actividad en España, por muchos inmigrantes africanos en situación irregular, sobre todo por los recién llegados.

\section{RÉSUMÉ}

Les africains sont le collectif étranger en Espagne qui plus a augmenté pendant le dernière décennie, leur majorité s'́a instalé irregulierment, mais plus tard ils ont eté regularisés en proportion élevé, surtout à travers de les Régularisations exceptionnelles (1985-86, 1991, 1996) et des permis de travail octroiyés dans les contingents annuels (1993-1998) pour les travailleurs étrangers non communautaires. Dans cette ligne on indique les principales actions proposées par la politique espagnole d'immigration. L'agriculture mediterranéenne de l'Espagne, dû à ses caracteristiques, peut servir de «porte», ou premier activité en Espagne, par beaucoup des immigrés africains en situation irrégulièr, surtout par les travailleurs nouveau venus.

La inmigración extranjera en España es un tema de actualidad permanente desde la promulgación en 1985 de la «Ley de extranjería», o «Ley Orgánica 7/1985, de 1 de julio, sobre derechos y libertades de los extranjeros en España» (BOE de 3-7-1985) y de su

* Comunicación presentada al Coloquio internacional «Migration clandestine: enjeux et perspectives», organizado en Rabat, Faculté de Droit (29-30 abril 1999), por la Association Marocaine d'Etudes et de Recherches Sur les Migrations. Investigación realizada en el Proyecto SEC 98-0628, financiado por la CICYT, Programa Nacional de Estudios Sociales y Económicos, Plan Nacional de I+D. 
Reglamento de ejecución (BOE de 12-6-1986); las críticas sociales recibidas por esta Ley y su reglamento han sido la causa de su modificación por Real Decreto 155/1996, de 2 de febrero. Esta primera reglamentación de la presencia de extranjeros en España respondía al acelerado e inesperado incremento de los inmigrantes que se producía desde principios de los años 1980, a resultas del cierre de fronteras en los países europeos de inmigración tradicional, mientras el mercado laboral español sufría altísimas cifras de desempleo - tasa de paro de 21'6 \% en 1985- (Gozálvez, 1990).

Los extranjeros procedentes de países desarrollados, aún son casi la mitad del total de los que residen en España (Cuadro I); sin embargo, los inmigrantes originarios de países en desarrollo (africanos, latinoamericanos, asiáticos) son los que concentran la atención, las inquietudes y las actuaciones no sólo de la Administración española, sino también de los medios de comunicación, de las organizaciones de apoyo al inmigrante, de la opinión pública, así como de los investigadores. Los africanos, debido a razones de proximidad geográfica, de crecimiento demográfico y de dificultades socioeconómicas son, sin duda, los protagonistas de estas atenciones.

Cuadro I

RESIDENTES EXTRANJEROS EN ESPAÑA SEGÚN LA NACIONALIDAD, 1985-1998

\begin{tabular}{|c|c|c|c|c|}
\hline Origen & 1985 & 1991 & 1998 & $\begin{array}{c}\text { Var. anual } \\
1991-98\end{array}$ \\
\hline Europa & 158.211 & 180.735 & 330.528 & $9^{\prime} 00$ \\
\hline$\%$ & 65,4 & 50,1 & $45^{\prime} 9$ & \\
\hline Europa del Este & 711 & 6.377 & 21.306 & $18^{\prime} 81$ \\
\hline Estados Unidos y Canadá & 13.281 & 14.274 & 17.272 & $2 ’ 76$ \\
\hline$\%$ & 5,5 & 4,0 & 2,4 & \\
\hline Oceanía & 748 & 775 & 1.023 & $4^{\prime} 05$ \\
\hline $\begin{array}{c}\text { Total países desarrollados } \\
\%\end{array}$ & $\begin{array}{c}172.180 \\
71,2\end{array}$ & $\begin{array}{c}195.784 \\
54,3\end{array}$ & $\begin{array}{c}348.823 \\
48^{\prime} 5\end{array}$ & $8^{\prime} 60$ \\
\hline América Latina & 40.796 & 68.877 & 129.928 & $9^{\prime} 49$ \\
\hline$\%$ & 16,9 & 19,1 & 18,1 & \\
\hline Asia & 19.366 & 31.976 & 60.714 & $9 ’ 59$ \\
\hline$\%$ & 8,0 & 8,9 & 8,4 & \\
\hline África & 8.529 & 63.054 & 179.487 & $16^{\prime} 12$ \\
\hline$\%$ & 3,5 & 17,5 & $24^{\prime} 9$ & \\
\hline Marruecos & 5.817 & 49.513 & 140.896 & $16^{\prime} 11$ \\
\hline $\begin{array}{c}\text { Total países en desarrollo } \\
\%\end{array}$ & $\begin{array}{c}68.691 \\
28,4\end{array}$ & $\begin{array}{c}163.907 \\
45,4\end{array}$ & $\begin{array}{c}370.129 \\
51 ' 5\end{array}$ & $12 ’ 34$ \\
\hline Apátridas & 1.039 & 964 & 695 & $-4{ }^{\prime} 57$ \\
\hline Total & 241.910 & 360.655 & 719.647 & $10 ’ 37$ \\
\hline
\end{tabular}

Fuente: Ministerio del Interior. Dirección General de la Policía, Memoria (anual). Comisión Interministerial de Extranjería, Anuario Estadístico de Extranjería 1998. 
La mayoría de los inmigrados africanos se instalaron en España de modo irregular, frecuentemente ocupan empleos precarios e inestables, y según las encuestas realizadas a los españoles sobre sus actitudes hacia los inmigrantes extranjeros, los africanos son el colectivo que es juzgado con mayores problemas para su integración en España (Gozálvez, 1998 a).

\section{La inmigración africana, un flujo caracterizado por su crecimiento rápido y acceso irregular}

Las cifras de residentes africanos en España entre 1985 y 1998 muestran incrementos muy importantes, de 8.529 a 179.487 (Cuadro I). Su peso relativo en la población española es aún muy escaso - 0`4\% de africanos en 1996, y 1'5\% si consideramos al conjunto de los extranjeros-, pero las bajas proporciones globales deben ser matizadas desde el punto de vista geográfico, ya que los africanos ofrecen llamativas concentraciones (en Madrid, Barcelona y litoral mediterráneo). Por otra parte, tal como se ampliará, son evidentes las dificultades para evaluar el número exacto de estos inmigrantes en España, debido a los altos contingentes que se encuentran en situación irregular, permanentemente renovados.

Después de la regularización extraordinaria de 1991, que tanto afectó positivamente a los africanos, este colectivo continental ha continuado con incrementos muy intensos, de 16`12\% anual entre 1991 y 1998. Los marroquíes, que sólo eran 5.817 según las cifras oficiales de 1985, en 1998 suman 140.896, es decir son la nacionalidad extranjera más numerosa en España, seguidos a distancia por los ingleses, 74.419, o por los peruanos, 24.879, si nos referimos a los procedentes de países en desarrollo. Si contabilizamos sólo a los inmigrantes que proceden de países poco desarrollados (africanos, latinoamericanos, asiáticos), los residentes africanos en España son, en 1998, el 48\% de este total (Cuadro I), y el 52\% (91.370) de sus trabajadores; de éstos, son marroquíes 73.287, mientras los peruanos, segundo colectivo extranjero en número de trabajadores, sólo alcanzan 15.910 en 1998.

Los elevados incrementos de los inmigrantes africanos en España se han producido sobre todo a través de la inmigración irregular, después legalizados en alta proporción con las regularizaciones extraordinarias (más de 110.000) o mediante los permisos de trabajo ofertados en los contingentes anuales para trabajadores extracomunitarios, establecidos desde 1993 (más de 45.000 contratos para africanos entre 1993 y 1998).

\section{La política de inmigración en España}

Las políticas de inmigración son fuentes básicas para conocer e interpretar el desarrollo de los flujos migratorios. En el caso de España las recientes políticas sobre la inmigración procedente de los países en desarrollo han evolucionado con notable celeridad; ciertas disposiciones han realizado planteamientos sin duda positivos, sobre todo si tenemos en cuenta el notable deterioro que padece el mercado laboral español y la previsión de crecimiento exponencial para estos inmigrantes.

En el desarrollo de la política de inmigración pueden diferenciarse tres etapas, apoyadas en sendos documentos básicos:

A) Durante los años 1985-1990 la inmigración es percibida por los españoles con inquietud, debido al fuerte incremento de los inmigrantes que se asientan en España de modo irregular, y que se concentran en ciertas zonas geográficas (Madrid, Cataluña), 
donde padecen condiciones muy precarias de trabajo y alojamiento, lo que es denunciado por los medios de comunicación. El gobierno inicia entonces actuaciones contra estos flujos irregulares generalizados, apoyado en la «Ley de Extranjería» (1985) y su Reglamento de ejecución (1986). De acuerdo con esta Ley se realiza la primera regularización extraordinaria de extranjeros en 1985-86.

B) Entre 1990 y 1994 se desarrolla una política de inmigración más activa y socialmente más completa, que pretende aportar solución a la notable acumulación de inmigrantes en situación irregular, localizados fundamentalmente en Cataluña, en Madrid y en las provincias litorales del Mediterráneo. Esta segunda etapa se apoya en el documento Situación de los extranjeros en España. Líneas básicas de la política española de extranjería (Aragón; Chozas, 1993, pp. 181-217), aprobado por el Parlamento español en diciembre de 1990. Entre los efectos más destacados de este documento, hay que señalar los siguientes: 1) la regularización extraordinaria de trabajadores extranjeros realizada en 1991; 2) la remodelación y creación de organismos públicos relacionados con la inmigración (Dirección General de Migraciones, 1991; creación de Oficinas de Extranjeros, 1991, y de la Comisión Interministerial de Extranjería, 1992); 3) creación de los cupos o Contingentes anuales de permisos de trabajo para extranjeros no comunitarios; 4) intensificación de las actuaciones contra la inmigración irregular (vigilancia de fronteras, desarticulación de redes de inmigración ilegal, inspecciones contra empresarios que emplean ilegalmente a extranjeros).

C) La tercera etapa se inicia en 1994 y queda definida por el Plan para la Integración Social de los inmigrantes (Ministerio de Asuntos Sociales, 1995), dirigido a los inmigrantes que ya residen en España en situación regular; su vigencia inicial de cuatro años, se prolonga al bienio 1999-2000; desde 1997 (Real Decreto 140/1997, de 31 de enero) este Plan también incluye las acciones a favor de los solicitantes de asilo, de los refugiados y de los desplazados (Instituto de Migraciones y Servicios Sociales -IMSERSO_, 1998). Como en las etapas anteriores, además de las actuaciones que caracterizan a cada una de ellas, se perfeccionan las acciones ya iniciadas anteriormente, sobre todo en la que concierne al control de los flujos ilegales.

Junto a la integración social de los inmigrantes, el Plan también establece otras dos grandes líneas de actuación, como son la cooperación para el desarrollo de los países emisores de inmigrantes y el establecimiento de contingentes que puedan ser asumidos por la sociedad española. La ejecución del Plan para la integración de los inmigrantes, aunque es de iniciativa gubernamental, busca ser llevado a término con la colaboración de las Administraciones Autonómicas y Municipales, así como de las organizaciones sociales y asociaciones de inmigrantes. Esta política de integración pretende lo participación activa de toda la sociedad.

Como apoyo al Plan de integración, en 1995 se crearon dos organismos: a) el Foro para la Integración Social de los Inmigrantes —FORO_, como cauce para la consulta y diálogo entre las Administraciones públicas, las organizaciones sociales y las asociaciones de inmigrantes; b) el Observatorio Permanente de la Inmigración —OPI—, que recoge y publica información para conocer, evaluar y diagnosticar los asuntos relativos a la inmigración y orientar las acciones conducentes a la integración. La recogida de información se inicia en los municipios, para terminar en la D.G. de Migraciones, aunque el OPI también realiza seguimientos de las políticas de inmigración en otros países, y realiza y publica estudios y estadísticas que faciliten su labor última, el conocimiento e integración de los inmigrantes. 
Entre las actividades derivadas de este Plan de integración de los inmigrantes, hay que resaltar la redacción y aprobación en 1996 de un nuevo Reglamento de ejecución de la «Ley de Extranjería» de 1985 (BOE de 23-02-1996), que sustituye al de 1986; entre sus aspectos más destacables hay que citar las disposiciones destinadas a facilitar la reagrupación familiar de los inmigrantes, así como su estabilidad legal, mediante la concesión de permisos de larga duración. La disposición transitoria tercera de este nuevo Reglamento prevee una nueva regularización extraordinaria para los extranjeros que se hallaran en situación irregular, aunque esta regularización sólo fue solicitada por 24.691 inmigrantes (Cuadro II).

Para el bienio 1999-2000, el Plan para la integración social de los inmigrantes se ha impuesto como prioridades, entre otras: impulsar medidas de formación y promoción laborales; propiciar la eliminación de barrearas de acceso al empleo, a la vivienda y a la educación; fomentar el diálogo entre la Administración y los movimientos asociativos, así como fomentar la solidaridad de la sociedad española hacia los inmigrantes mediante la difusión de los valores de tolerancia, sobre todo en los medios de comunicación; también se pretende fomentar la actividad del OPI, consolidando su red territorial (IMSERSO, 1998).

\section{Las regularizaciones extraordinarias de inmigrantes}

La regularización de 1985-86 fue solicitada por 43.815 extranjeros, de los que 38.181 tuvieron respuesta positiva (Aragón; Chozas, 1993, p. 26). Los africanos fueron el 37\% del total de solicitantes (Cuadro II). Por cada 100 africanos residentes en España en 1985 en situación regular, se presentaron 188 solicitudes de regularización; los africanos subsaharianos fueron los que presentaron mayor proporción de peticiones de regularización, 154 por cada 100 residentes, lo que se relaciona con su presencia más consolidada y organizada en Cataluña (Gozálvez; López, 1999). Sin embargo, todos los analistas coincidieron en valorar que los resultados globales de esta primera regularización extraordinaria subestimaban el número de inmigrantes en situación irregular. De hecho, el colectivo PASS, en un trabajo específico realizado para la D.G. de Migraciones a principios de 1990, estimabas que el número de extranjeros en situación irregular en España oscilaba entre 172.000 y 259.000, con dos grandes concentraciones en Cataluña (34\% del total) y en Madrid (34\%); del total de estos inmigrantes irregulares, el 60\% serían africanos, sobre todo marroquíes (Marcos Sanz, 1990).

Parte del fracaso de la regularización de 1985-1986 se puede atribuir a la inexperiencia de la Administración en este tipo de operaciones y a la valoración incierta de esta regularización por parte de los inmigrantes; de hecho, en aquellos años los inmigrantes en situación irregular — status que estaba generalizado- se desenvolvían en España sin excesivos problemas legales. El ejemplo de los africanos subsaharianos asentados en la comarca del Maresme, en el litoral al norte de la ciudad de Barcelona, ilustra bien la situación indicada: en 1983 los africanos de origen subsahariano regularizados en la provincia de Barcelona eran 784, mientras durante ese mismo año el Gobierno Civil de Barcelona censaba, sólo en la comarca del Maresme, un total de 2.092 africanos con este mismo origen y en situación irregular; de este total, el 93\% eran gambianos, el 71\% tenía entre 16 y 30 años de edad, el 82\% había llegado a España por el aeropuerto de Madrid-Barajas y el $83 \%$ estaban ocupados, casi todos en la agricultura. En los regadíos frutícolas del Segrià (provincia de Lérida, Cataluña), se localizaba otra colonia de subsaharianos con características muy similares a las indicadas (Gozálvez, 1990). 
Cuadro II

ESPAÑA. SOLICITUDES PRESENTADAS EN LAS REGULARIZACIONES EXTRAORDINARIAS DE INMIGRANTES EXTRANJEROS

\begin{tabular}{|c|c|c|c|c|c|c|}
\hline Nacionalidad & $1985-86$ & $\begin{array}{c}\text { \% de solicitudes } \\
\text { en relación a } \\
\text { los residentes } \\
\text { en } 31-X I I-1985\end{array}$ & 1991 & $\begin{array}{c}\% \text { de solicitudes } \\
\text { en relación a } \\
\text { los residentes } \\
\text { en 31-XII-1990 }\end{array}$ & 1996 & Totales \\
\hline África & 16.024 & 188 & 76.464 & 297 & & \\
\hline Magreb & 8.019 & 128 & 63.664 & 360 & 8.865 & 80.548 \\
\hline Marruecos & 7.868 & 135 & 58.273 & 350 & 7.826 & 73.967 \\
\hline Resto de África & 8.005 & 354 & 12.800 & 156 & & \\
\hline América Latina & 8.651 & 21 & 32.024 & 51 & & \\
\hline Asia & 5.728 & 30 & 15.136 & 52 & & \\
\hline Resto & 13.412 & 8 & 11.211 & $23^{*}$ & & \\
\hline Total & 43.815 & 18 & 134.845 & $81^{*}$ & 24.691 & 203.351 \\
\hline Regularizaciones & 38.181 & & 115.024 & & 21.283 & 174.488 \\
\hline
\end{tabular}

* No se contabilizan los residentes de la CEE.

FuENTE: Para 1985-86, Ministerio del Interior, Dirección General de la Policía, Memorias anuales.

Para 1991, Aragón Bombín, R.; Chozas Pedrero, J., 1993, ob.cit.; los datos están referidos al 15-5-1993: de las solicitudes presentadas, 128.068 corresponden a trabajadores y 6.777 a familiares; de las regularizaciones concedidas, 109.135 corresponden a permisos de trabajo y 5.884 a familiares.

Para 1996, Ministerio de Trabajo y Asuntos Sociales. Dirección General de Ordenación de las Migraciones, Informe de Gestión (30-7-1997). Del total de solicitudes, 17.676 corresponden a permisos de trabajo y residencia, y 7.015 a permisos de residencia; de las primeras, se han concedido 14.653 permisos de trabajo y residencia, y 6.630 de residencia, Ministerio del Interior, Dirección General de la Policía, Memoria de actividades 1997.

De las 43.815 demandas de regularización presentadas en 1985-86, el 30\% lo fueron en Cataluña, el $14 \%$ en Madrid, el $12 \%$ en Andalucía y el $8 \%$ en la Comunidad Valenciana. Es decir, los inmigrantes irregulares, y especialmente los africanos, se localizaban —igual que ocurre con el mapa actual de estos inmigrantes - en torno al Mediterráneo, y sobre todo en las dos grandes metrópolis del país, Barcelona y Madrid; sus ocupaciones fundamentales eran la agricultura, construcción y venta ambulante.

La regularización extraordinaria de trabajadores extranjeros de 1991 (que se prolongó hasta el 10 marzo de 1992 para los familiares dependientes de los trabajadores regularizados), fue solicitada por 134.845 inmigrantes, de los que obtuvieron respuesta positiva 109.135 trabajadores y 5.884 familiares. Los africanos fueron de nuevo el primer colectivo en número de solicitudes, pero ahora con mucha más preeminencia que en 1985-86: sus 76.464 solicitudes de regularización — de las cuales 58.273 fueron de marroquíes- equivalen a 297 inmigrantes en situación irregular por cada 100 residentes en situación regular en 1990; las solicitudes correspondientes a nacionalidades de América Latina (Cuadro II) muestran una tasa de inmigrantes irregular mucho más baja: 51 solicitantes por cada 100 residentes, y 52 en el caso de los asiáticos. 
Es patente, pues, cómo los inmigrantes africanos, particularmente los marroquíes y argelinos, son los protagonistas destacados de la inmigración irregular procedente de países menos desarrollados. Estos inmigrantes llegaron a España de forma clandestina o bien como turistas y estudiantes, pero reconvertidos después a trabajadores-residentes en situación irregular. La imposibilidad de acceder a otros países europeos de inmigración laboral tradicional, donde existían mejores perspectivas económico-laborales que en España, es sin duda la causa determinante para que el $80 \%$ de los inmigrantes africanos en España declaren que éste es su primer país de inmigración; en efecto, la decisión de elegir España como país de emigración es casi incompatible con las «inconfortables» condiciones de trabajo que estos inmigrantes encuentran aquí. Su generalizado acceso irregular a España queda corroborado, además, cuando el 86\% de los africanos regularizados en 1991 declara que llegó como «turista», mientras que sólo un 4`6\% había llegado con visado para trabajar (encuesta realizado por la Dirección General de Migraciones a los inmigrantes regularizados en 1991 (Aragón; Chozas, 1993)).

Obviamente esta inmigración también es facilitada por las posibilidades de trabajo irregular que estos inmigrantes confían encontrar en España, sobre todo en la agricultura, ayudados por los apoyos e informaciones que les aportan los familiares y amigos de estos inmigrantes ya asentados en España (Gozálvez, Dir., 1995). En cualquier caso, esta inmigración laboral, «contradictoria» con las escasas y marginales ofertas de trabajo que los africanos pueden encontrar en España, está motivada en el fondo porque el inmigrante percibe las diferencias de renta y las posibilidades de futuro que ofrece España en comparación con su país de origen, las cuales confía alcanzar en el país de destino; además, éste también es valorado como etapa de espera para acceder a otros países con mejores perspectivas de empleo y de salario. Por otra parte, los inmigrantes piensan que su situación socioeconómica en España tiene posibilidades de mejorar una vez conseguida su regularización laboral y residencial (Gozálvez; López, 1999).

La regularización extraordinaria de 1996 fue de alcance menor, tanto en su difusión como en sus resultados. Del total de 24.691 solicitudes de regularización (entre el 23-4 y 23-8-1996), el 36\% fueron presentadas por magrebíes. Como en la regularización de 1991, en esta ocasión también se hizo una encuesta a los extranjeros que solicitaban su regularización (CIS, 1996), cuyos resultados indican que persisten las características deducidas de consultas anteriores (Aragón; Chozas, 1993; Gozálvez, Dir., 1995).

En efecto, entre los inmigrantes en situación irregular encuestados al solicitar regularización en 1996, un 52\% eran africanos, 29\% latinoamericanos y $11 \%$ asiáticos; un $60 \%$ tenía entre 18 y 34 años de edad. En su mayor parte no eran recién llegados, sino que su presencia en España, al menos como primera inmigración, era ya antigua: el 18\% había venido por primera vez antes de 1985, el $42 \%$ entre 1986 y 1990 , y un $39 \%$ entre 1991y1995. El 80\% había emigrado sólo a España, mientras el resto, antes de venir a España había estado en otros países, fundamentalmente en los europeos mejor situados económicamente, como Francia o Alemania. Las provincias de España donde residen estos inmigrantes son principalmente Madrid (38\%), Barcelona (29\%) y el resto del litoral mediterráneo (58\%), especialmente Valencia, Almería y Murcia (zonas de agricultura intensiva). Los inmigrantes que llegaron a España con visado para trabajar continúan siendo minoría, 9’3\%, mientras el resto declara que llegó principalmente como turista (69\%). La mayoría de estos inmigrantes en situación irregular tuvieron en su momento distintos tipos de permiso de trabajo y de residencia, pero la irregularidad les sobrevino fundamentalmente por denegación de la renovación de sus permisos (37\%) o porque el permiso caducó y el inmi- 
grante no solicitó su renovación (37\%). Pese a su situación irregular, el 55\% de estos inmigrantes estaba trabajando en España; la agricultura era su trabajo mayoritario $(21 \%)$, seguida por diversas actividades en el sector servicios (en hogares, hostelería, venta ambulante, etc.); en muy alta proporción (45\%) trabajaban sólo con acuerdos verbales, bien porque se les había negado un contrato escrito (46\%) o simplemente porque los inmigrantes no lo habían pedido (26\%); la mayor parte de estos inmigrantes, $58 \%$, tiene familiares trabajando en España. El 40\% declaran intención de permanecer para siempre en España, y otro $48 \%$ condiciona su permanencia a «su situación». La reagrupación familiar la tiene prevista el $40 \%$ de estos inmigrantes. Finalmente, aunque el $83 \%$ de los encuestados declara que se siente «más bien satisfecho» con su situación general en España, su status económico no es holgado, pues el 39\% dicen ingresar menos de 75.000 pesetas mensuales.

Aunque en ninguna de las encuestas que hemos consultado o realizado a inmigrantes africanos (Gozálvez, Dir., 1995) se mencionan los medios clandestinos que suelen utilizar para llegar a España, éstos son muy vigentes. El medio más frecuente parece ser la utilización de «pateras» o pequeñas embarcaciones, que realizan el trayecto entre las costas cercanas al Estrecho de Gibraltar; lo más frecuente es que recalen en el litoral de la provincia española de Cádiz, pero también llegan a las costas de Almería, de Málaga o incluso a las islas Canarias más próximas al continente africano. En 1997, los inmigrantes clandestinos llegados por vía marítima e interceptados por la policía española suman 1.881, de los que 1.566 utilizaron «pateras», y entre éstos 1.373 llegaron a las costas de la provincia de Cádiz (Ministerio del Interior, 1997 b). En 1992, según el Gobierno Civil de Cádiz, el número de inmigrantes clandestinos llegados en «pateras» y detenidos en dicha provincia fue de 1.162, entre los que había inmigrantes de más de 20 nacionalidades africanas (Gozálvez, 1998 b). Otra modalidad importante de acceso clandestino por vía marítima es la de polizones: en 1997 los controlados por la policía española suman 832 , de los que más del $90 \%$ eran africanos, sobre todo magrebíes; el puerto de destino más frecuente es el de Barcelona, aunque todos los puertos españoles están incluidos en esta estadística (Ministerio del Interior, 1997 a).

\section{Los contingentes de trabajadores extranjeros no comunitarios}

Los contingentes o cupos anuales de trabajadores no comunitarios fueron establecidos por el Gobierno español en 1993; su objetivo es regular estos flujos y garantizar la cobertura de aquellas ofertas de empleo no atendidas en el mercado nacional de trabajo, en ciertos sectores y zonas geográficas determinadas.

Las solicitudes presentadas a cada contingente (Cuadro III), sin duda pueden ser interpretadas como indicador de la bolsa de trabajadores extranjeros en situación irregular, a completar, obviamente con otros trabajadores que todavía no se han introducido en estos «mecanismos» administrativos, y con familiares de estos trabajadores. La serie de contingentes que ofrece el Cuadro III, muestra cómo en 1993 se acusa la inexperiencia de los trabajadores extranjeros ante esta nueva oportunidad de regularización; es una situación que recuerda el «fracaso» de la primera regularización extraordinaria de 1985-86. El fortísimo aumento de solicitudes que se produce en1997, 70.639 frente a 37.214 en 1995, resalta la acumulación de trabajadores en situación irregular que se produce al no haber sido convocado contingente en 1996; esta omisión está relacionada con la convocatoria en ese año de la tercera regularización extraordinaria de extranjeros realizada con motivo de la promulgación del nuevo Reglamento de la «Ley de Extranjería». En cualquier caso, las 77.276 solicitudes de trabajadores en situación irregular presentadas en 1999 — datos a 12-4-1999, 
Cuadro III

CONTINGENTE DE TRABAJADORES EXTRANJEROS NO COMUNITARIOS

\begin{tabular}{|c|c|c|c|c|c|c|c|c|c|}
\hline Año & Contingente & Solicitudes & \multicolumn{7}{|c|}{ Permisos de trabajo concedidos } \\
\hline & & & Agricultura & Construcción & \begin{tabular}{|c|} 
Empleadas del \\
hogar
\end{tabular} & $\begin{array}{c}\text { Otros } \\
\text { Servicios }\end{array}$ & Total & Africanos & Marroquíes \\
\hline 1993 & 20.600 & 6.415 & 160 & & 6.346 & 714 & 5.220 & 679 & 586 \\
\hline 1994 & 20.600 & 37.277 & 8.453 & 737 & 13.728 & 2.686 & 25.604 & 12.763 & 9.714 \\
\hline 1995 & 25.000 & 37.214 & 7.855 & & 12. & & 19.946 & 9.939 & 8.387 \\
\hline 1997 & 24.690 & 70.639 & 6.631 & 451 & 12.197 & 2.332 & 21.611 & 9.073 & 7.689 \\
\hline 1998 & 28.100 & 62.697 & 8.700 & 941 & 14.662 & 3.893 & 28.095 & 12.929 & 11.131 \\
\hline $1999 *$ & 30.000 & 77.276 & & & & & & & \\
\hline
\end{tabular}

*Datos a 12-4-99

FuENTES: Ministerio de Trabajo y Asuntos Sociales. Dirección General de Ordenación de las Migraciones, Anuario de migraciones 1996 y 1997.

Para 1998 y 1999, Ministerio de Trabajo, Dirección General de Ordenación de las Migraciones. Datos provisionales.

antes de finalizar el plazo legal para estas peticiones-, ilustran sobre la progresiva acumulación de los trabajadores en situación irregular, a pesar de que los contingentes aumentaron de 20.600 autorizaciones en 1994 a 28.000 en 1998.

Como se aprecia en el Cuadro III, los permisos de trabajo ofertados en los contingentes favorecen a dos sectores: las empleadas del hogar, que sobrepasan la mitad de los permisos concedidos cada año (59.024 entre 1993 y 1998), y los trabajadores agrícolas (31.799 entre 1993 y 1998) con casi un tercio del total; estos son en general africanos, que en 1998 ocupan el $90 \%$ del total de los empleos agrícolas ofertados a los extranjeros, y representan el $60 \%$ del total de trabajadores africanos; las empleadas de hogar africanas también alcanzan una notable representación, el $20 \%$ de estos empleos. Según tendencias ya establecidas, las empleadas del hogar se concentran en Madrid (48\% del total en 1998) y en Barcelona (27\%), mientras los trabajadores agrícolas se distribuyen por toda la costa mediterránea $(73 \%)$, pero con fuerte concentración en la agricultura intensiva de Almería (25\% del total) y de Murcia (22\%). De acuerdo con el volumen residencial y laboral de los africanos entre los extranjeros no comunitarios, su participación en los contingentes de trabajadores alcanza al 45\% del total (media de 1994-98).

\section{La agricultura mediterránea española, una «puerta» para la inmigración africana}

El sector agrario español emplea oficialmente a casi 35.000 extranjeros en 1998 (Comisión Interministerial de Extranjería, 1998) casi todos africanos, aunque en este sector persisten importantes bolsas de trabajadores en situación irregular. El trabajo agrícola suele ser la primera actividad en España de buena parte de estos trabajadores recién llegados, pero su objetivo es, sin ninguna duda, obtener trabajo en los sectores secundario y terciario, al que pueden acceder una vez reglada su situación laboral en España (Gozálvez, Dir., 1995). De esta forma, la agricultura mediterránea puede servir de «puerta» para los inmigrantes africanos en situación irregular. 
El rechazo generalizado que muestran los trabajadores africanos al trabajo agrícola en España se explica por causas variadas, entre las que destacan el mayoritario origen urbano de los recién llegados, y las discriminaciones y situaciones especialmente negativas - alojamiento precario, ganancias irregulares y menguadas, etc.- que sufren estos trabajadores de la agricultura, sobre todo a resultas de su frecuente trabajo itinerante debido a los calendarios agrícolas, a la estructura minifundista y familiar de las explotaciones intensivas - hortícolas, frutícolas- y a las necesidades que éstas tienen de empleo relativamente cuantioso pero con acentuada temporalidad.

Así, las peculiaridades de este trabajo agrario — una de las pocas actividades que ofrecen actualmente ciertas posibilidades de empleo-, aunque resultan poco atractivas, e incluso negativas, para el proyecto migratorio de los africanos, son aceptadas «porque no hay otro trabajo» y porque este trabajo es como una «puerta» que permite el acceso a otros sectores laborales una vez conseguida la ansiada regularización laboral. La elevada irregularidad que padecen estos trabajadores está pues, permanentemente renovada con los inmigrantes recién llegados (Gozálvez; López, 1999. Narbona, 1993) y los posteriores trasvases a empleos de otros sectores económicos.

Las perspectivas de la inmigración africana permanecen, pues, inacabadas, aunque, en cualquier caso, el desarrollo socioeconómico al sur del Mediterráneo es el horizonte ineludible tanto para las sociedades emisoras como para las receptoras de esta inmigración, actualmente «forzada» $\mathrm{y}$ en buena parte irregular, y por tanto insatisfactoria para todos sus protagonistas.

\section{Bibliografía}

ARAGÓN BOMBÍN, R.; CHOZAS PEDRERO, J. (1993), La regularización de inmigrantes durante 1991-1992, Madrid, Ministerio de Trabajo, 471 pp.

CENTRO DE INVESTIGACIONES SOCIOLÓGICAS -CIS- (1996), Regularización de inmigrantes (Encuesta a extranjeros en situación irregular), Estudio n ${ }^{\circ} 2.216$, mayoagosto 1996. Se realizaron 1.980 encuestas en las provincias de Madrid, Barcelona, Málaga, Las Palmas, Valencia, Alicante, Almería, Murcia y Girona, donde se concentraba más del $80 \%$ de los solicitantes de regularización.

COMISIÓN INTERMINISTERIAL DE EXTRANJERÍA (1998), Anuario Estadístico de Extranjería, 1998, Madrid.

GOZÁLVEZ PÉREZ, V. (1990), «El reciente incremento de la población extranjera en España y su incidencia laboral», Investigaciones Geográficas, núm. 8, pp. 7-36.

GOZÁLVEZ PÉREZ, V. (1992), «Inmigraciones recientes de extranjeros a España», III Jornadas de la población española. Ponencias y Relatorías, Grupo de Población de la A.G.E.; Departamento de Geografía de la Universidad de Málaga, pp. 9-38.

GOZÁLVEZ PÉREZ, V., DIR. (1995), Inmigrantes marroquíes y senegaleses en la España mediterránea, Valencia, Generalitat Valenciana, Conselleria de Treball i Afers Socials, 440 p.

GOZÁLVEZ PÉREZ, V. (1998a), «La percepción del Mediterráneo a través de la inmigración: las actitudes de los españoles hacia los magrebíes», Investigaciones Geográficas, núm. 20, Universidad de Alicante, pp. 5-18.

GOZÁLVEZ PÉREZ, V. (1998b), «Política de inmigración y presencia africana en la agricultura mediterránea de España», in Checa, F. (edit.), Africanos en la otra orilla, Barcelona, Icaria, pp. 19-59. 
GOZÁLVEZ PÉREZ, V.; LÓPEZ TRIGAL, L. (1999), «Jornaleros extranjeros en el campo español», Ería, (en prensa).

INSTITUTO DE MIGRACIONES Y SERVICIOS SOCIALES -IMSERSO- (1998), Documento de desarrollo del Plan para la Integración Social de Inmigrantes y Refugiados para el bienio 1999-2000, Madrid, Subdirección General de Promoción Social de la Migración y de Programas para Refugiados, 35 pp. (mecanografiado).

MARCOS SANZ, R. DE; ÁlVAREZ PRIETO, J.J.; ROJO ALCALDE, J.; KHABA LUANDA, A., Mapa de los trabajadores extranjeros en situación irregular en España, marzo 1990, 110 pp. (mecanografiado).

MINISTERIO DE ASUNTOS SOCIALES (1995), Plan para la Integración Social de los Inmigrantes, Madrid, $71 \mathrm{pp}$.

MINISTERIO DEL INTERIOR. DIRECCIÓN GENERAL DE LA POLICÍA, (1997a), Estadística de Extranjería y Documentación, 1997, Madrid, 303 pp.

MINISTERIO DEL INTERIOR. DIRECCIÓN GENERAL DE LA POLICÍA (1997b), Memoria de Actividades 1997, Madrid, 237 p.

MINISTERIO DE TRABAJO, (1997), Estadística de permisos de trabajo a extranjeros 1997, Madrid, $104 \mathrm{p}$.

NARBONA REINA, L.M. (1993), Marroquies en Viladecans. Una aproximación al tema de la inmigración, Ajuntament de Viladecans, 193 pp. 